\title{
Live issues: the classification of North American mammals
}

\section{Malcolm C. McKenna}

The Mammals of North America, 2nd Edn. By E. Raymond Hall. Two volumes, pp.1,181. ISBN Vol. 1 0-471-05443-7; ISBN Vol. 2 0-471-05444-5. (Wiley: 1981.) $\$ 59.85, £ 33.25$ per volume; two-volume set $\$ 106.40$, £59.15.

E. RAYMOND Hall and Keith R. Kelson's compilation of the species-level taxonomy and geographical distribution of living North American mammals, published in 1959 , has long been out of print. Now Hall has produced a partly corrected second edition, updated to 1977 and even beyond, but the new version is still marred by many jarring anachronisms.

As before, the work is divided into two volumes. After a brief introduction, the first volume begins with marsupials and then marches through the insectivores, bats, primates, edentates, lagomorphs and the first half of a long section on rodents. The second volume completes the rodents and then moves to the cetaceans, carnivores, sirenians, perissodactyls and artiodactyls. In all of the entries, attention is focused on the traditionally-studied details of coat colour and measurements of the body, limbs, ears and tail - the sort of information one needs when setting out to match a stuffed mouse with specimens in the neatly arranged rows of museum trays. Many illustrations and occasional discussions of skull morphology are also provided, although, for me, details of some dentitions are depicted at too small a scale. There are helpful indexes, a glossary and a long bibliography, and a "how to do it" section deals with collection of specimens, preparation and data preservation.

I believe that the work is still flawed by its typological, philatelic approach - the preoccupation with segregating on the basis of a few selected criteria, mainly Rubicons of size, what might as well be inanimate, history-bereft objects. Although dichotomous keys are employed frequently, these have little phylogenetic rationale and do not deal with morphocline polarities as would be the case if the organisms were treated cladistically. No attempt is made to weed out sharedprimitive characters. Worse, in the keys geographical distributions are all too often used in place of biological characters just as stratigraphical position does not necessarily yield the correct identification

The Biochemistry of the Nucleic Acids, originally written by J.N. Davidson and first published in 1950, has recently appeared in a ninth edition. The new edition has been compiled by R.L.P. Adams together with four other authors at Glasgow University, and is a substantial revision of the last, 1976, edition. The book is published by Chapman \& Hall and costs $£ 8.50$ in paperback of fossils, geographical position does not necessarily give us the correct taxonomic allocation of living organisms. Biological taxa should be recognized by biological criteria alone. Let the stratigraphical and biogeographical chips fall where they may.

According to Hall, about 400 species and subspecies have been added to the living North American mammalian fauna since 1959 , bringing the present total up to 3,607. However, although myriads of named (and presumably approved) subspecies are listed and referenced, morphological evidence for their recognition is not presented. Rather, maps depict arbitrary boundaries between localities that produce "marginal specimens" of the putative subspecies. The characterizing features of these - if genuinely biological, and not merely geographically arbitrary or a relic of overly split typological taxonomy - must be sought either in the original literature or elsewhere. Perhaps, in some long-distant future revision, the subject of intraspecific variation can be handled quantitatively. Hall has made a start, but the job is immense.

Finally, Hall's treatment of higher taxonomic categories should be taken with a grain of salt. This is because he deals with members of the living fauna as though they had no history: he does not differentiate between primitive features and phylogenetically significant shared-derived ones. For example, he seems to be unaware that characters such as an inflected mandibular angle or epipubic bones are not merely metatherian hallmarks but characterize early eutherians as well. Nor does he record that jugal bones reach the glenoid fossa in paenungulates, not just in the Metatheria. Interested readers should also run through the list of mainly primitive features supposedly characterizing Polyprotodontia, Didelphidae or Insectivora (the latter stretched to include the conceptually indigestible macroscelidids). Hall's concept of the "Order Pinnipedia" and his separation of living sloths from megalonychid ground sloths by interlarding the Myrmecophagoidea into their midst will also raise palaeontological and cladistic eyebrows alike.

Hall's work will continue to be useful in spite of its conceptual shortcomings and his apparently stubborn refusal to modify adequately some sections of the first edition which many, even most, mammalogists found objectionable - those dealing with bears, Dama and Lasiurus, for example.

After all these grumblings, do I recommend the monograph? Yes, of course. After all, what better summary do we have?

Malcolm C. McKenna is in the Department of Vertebrate Paleontology at the American Museum of Natural History, New York.

\section{An abundance of beetles}

\section{M.E.G. Evans}

The Biology of the Coleoptera. By R.A. Crowson. Pp.802. ISBN 0-12-196050-1. (Academic: 1981.) £58, \$139.50.

WE LIVE in the age of the obscure beetle. Flowers, fleas, birds and butterflies are all much more obvious organisms, but there are more species in the order Coleoptera than there are in the class Angiospermae, and even, perhaps, than in the whole plant kingdom. Since this enormous species diversity is based upon a common body plan, the variations on this theme should be of great interest to evolutionary biologists as well as specialist entomologists. So where are the hosts of coleopteran biologists?

One reason why biological studies of beetles lag far behind their taxonomy may be a simple failure to appreciate the scope of the subject. What has been lacking until now has been a general biological text which deals with the numerous but scattered studies of beetles. It is just this sort of book which Dr Crowson has written; it is based on well over 1,000 references, including many from non-
English language literature, most of which is recent. However, it is more than a mere compendium of references. In most cases, the information on a topic has been summarized, digested and assimilated into a more general subject area in each of the 20 chapters of text, ranging from morphology and genetics to ecology and evolution. The basic approach is both functional and phylogenetic, although an extended treatment of classification is deliberately omitted. Nevertheless, a family classification is appended, and taxonomic groups in the text are given code numbers which refer to the phylogenetic chart following Chapter 20.

Inevitably, there are some blemishes. Over 300 figures are included, most of which are simple, clear, line drawings, but some have been drastically reduced for printing whilst a few are not reduced enough. Not surprisingly, some topics are discussed in less depth than others, but in most cases these differences in treatment reflect our different levels of comprehension of the subject. Indeed, this has enabled the author to point to obvious gaps 